\title{
J.0. Colla
}

JOHNSON CONTROLS, INC.

507 E. Michigan Street

Milwaukee, Wisconsin 53201

ABSTRACT

The element described for sensing the presence of nitrogen dioxide in the environment consists of a pyrolyzed polyaromatic polymer film having semiconductive properties. Nitrogen dioxide effects a change in the electrical resistance of the pyrolyzed polymer. The presence of nitrogen dioxide causes the electrical resistance of the element to decrease, and the magnitude of resistance change is a function of nitrogen dioxide concentration. Concentrations as low as $1.3 \mathrm{ppm}$ nitrogen dioxide can be readily and quickly sensed in an air environment.

\section{INTRODUCTION}

Some solid-state sensors, such as the Taguchi Gas Sensor, indicate the presence of oxidizable gases, such as hydrocarbons and carbon monoxide [1]. Another sensor, the Dolan Adsorptive Sensor, detects the presence of gases having a van der Waal's "a" constant above 6 [2]. While many of these gas sensors are capable of continuous and reversible detection, they are not specific to a particular gas. Considerable attention has been focused recently on the need for gas sensing devices that are highly selective for the detection of gaseous pollutants.

Efforts in our laboratory have focused on the development of solid-state gas detectors that respond reversibly to the presence of specific gases. The nitrogen dioxide sensor described in this paper is a product of this effort [3], [4].

The inherent tendency for many organic compounds to adsorb and/or absorb gases foretells their applicability for a gas sensing device. Vacuum pyrolysis of long chain polymers yields in some instances a semiconductive residue [5]. These two statements open the possibility of developing and using organic semiconductors as gas sensors and serve as the basis for the nitrogen dioxide sensor described in this paper.

\section{SENSOR CONFIGURATION AND FABRICATION}

The nitrogen dioxide gas sensor, which is shown in Fig. 1, consists of a pyrolyzed polymeric film that has a partially metallized surface, an alumina substrate for mounting the pyrolyzed film and contact tabs which provide a means to make electrical connections to the pyrolyzed film.
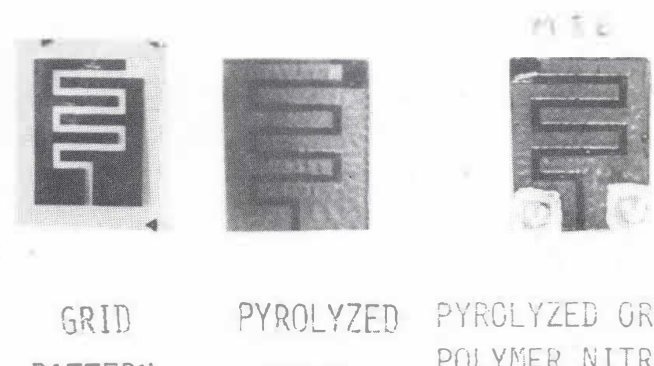

PATTERN

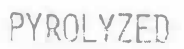

FILM

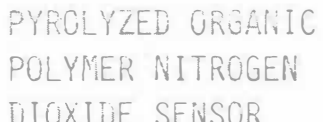

FIG, 1

The principal component of this sensor is a pyrolyzed polyimide film. Commercially available polyimide film (Kapton $\mathrm{H}$ ) from E.I. DuPont de Nemours \& Company, having a thickness of 0.001 inch, is metallized by electroless chemical methods. The metallization process involves the application of a thin nickel layer, and the subsequent application of a thin gold layer by means of electroless chemical techniques. Using a grid pattern negative and photofabrication methods, a selected portion of the metal layer in the form of a serpentine grid is removed from the surface of the polyimide film (see Fig. 1). In addition to outlining the active portion of the film, the gold layer provides noncorrosive electrical conductors and a means to make electrical connections. 
The metallized polyimide is pyrolyzed by placing it between porous graphite plates (maintains a flat film) and heating in a vacuum furnace. A typical pyrolysis process is performed in a vacuum of $1 \times 10^{-5}$ torr at a temperature of $610^{\circ} \mathrm{C}$ for 60 minutes. The pyrolysis process changes the electrical characteristics of the polyimide film from that of a dielectric to a semiconductor.

Pyrolysis is a complex chemical process dependent on temperature and time at

temperature. It is believed that non-mobile unsaturated valence states exist in the semiconductive polyaromatic polymer after pyrolysis. As shown in Fig. 2, the structure retains its aromaticity, tending toward a condensation of the aromatic rings. The exact mechanism of the pyrolysis is not fully established, but the resulting semiconductivity and gas sensing properties of the pyrolyzed polyimide film are believed to be due to its molecular structure [6].
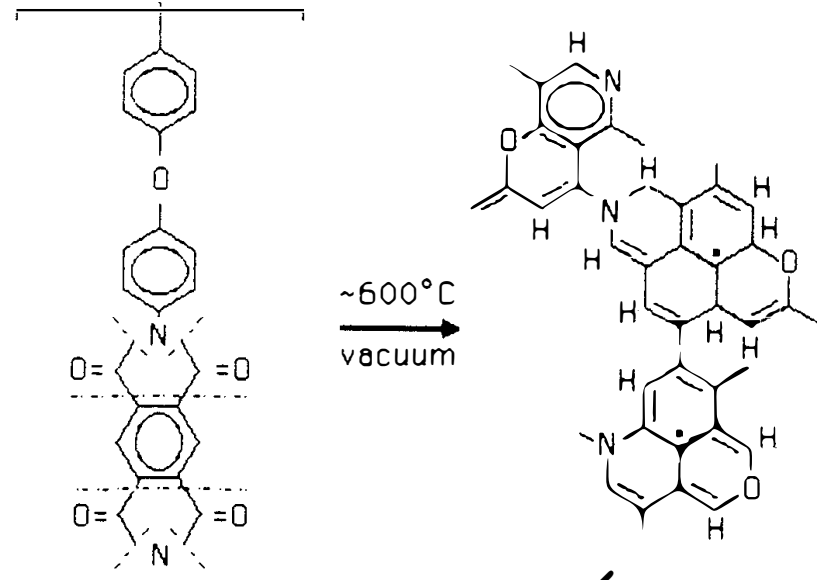

$2700^{\circ} \mathrm{C}$ vocuum

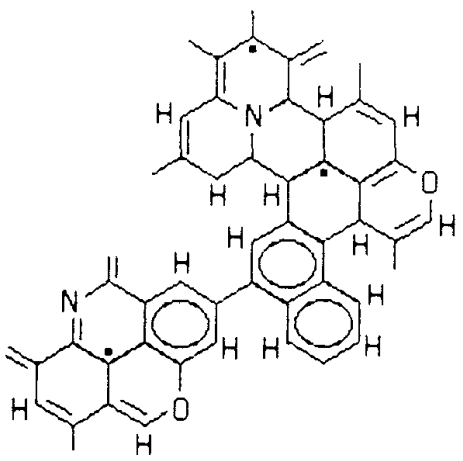

- = Unsoturgted volence stotes

FIG, 2
The pyrolyzed film is mounted on an alumina substrate as shown in Fig. 1 and 3 . The alumina substrate is not chemically reactive and is a good electrical insulator. It provides an ideal foundation for the fragile pyrolyzed polyimide film. The pyrolyzed film, having an approximate size of $1.27 \mathrm{~cm}$ by $1.016 \mathrm{~cm}$ is mounted on the alumina substrate with an epoxy resin.
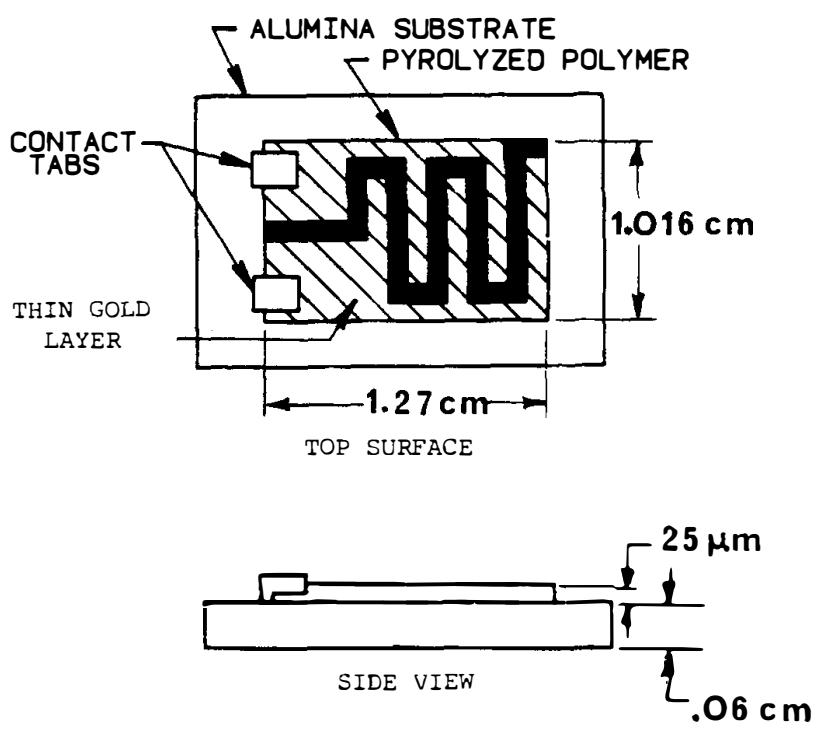

FIG. 3

Electrical wires cannot be soldered directly to the thin gold layer on the pyrolyzed film due to its fragile nature. A gold plated contact tab is bonded to each of the gold layer conductors on the polymer film using a gold filled epoxy resin. Lead wires are then soldered to the contact tabs (see Fig. 1).

\section{SENSOR CHARACTERISTICS}

The pyrolyzed polyimide sensor decreases in electrical resistance when exposed to nitrogen dioxide in an air environment (see Fig. 4 through 7). The short term response to various concentrations of nitrogen dioxide (from concentration certified gas cylinders), at an air flow rate of 12 SCIM is shown in Fig. 4 through 6 . The electrical resistance of the sensor decreases when exposed to air containing nitrogen dioxide, and the magnitude of resistance change is dependent on the concentration of nitrogen dioxide in the air. For example, the percent decrease in resistance after 6 minutes exposure to nitrogen dioxide is $15.0 \%, 5.7 \%$, and $4.3 \%$ respectively for nitrogen dioxide concentrations of $90 \mathrm{ppm}, 8 \mathrm{ppm}$, and $1.3 \mathrm{ppm}$. When the sensor responds to a change in nitrogen dioxide concentration, time is required for the element to reach equilibrium with the new concentration of 
nitrogen dioxide in air. In Fig.7, the response characteristics are shown for a step change in nitrogen dioxide concentration from $0 \mathrm{ppm}$ to $30 \mathrm{ppm}$ nitrogen dioxide in air. These response data are for a pyrolyzed polyimide film in a closed vessel containing air in which an ampoule of nitrogen dioxide was ruptured. The time it takes the resistance of the sensor to change $66.6 \%$ and $90 \%$ is 660 seconds and 1800 seconds respectively at a zero flow rate.
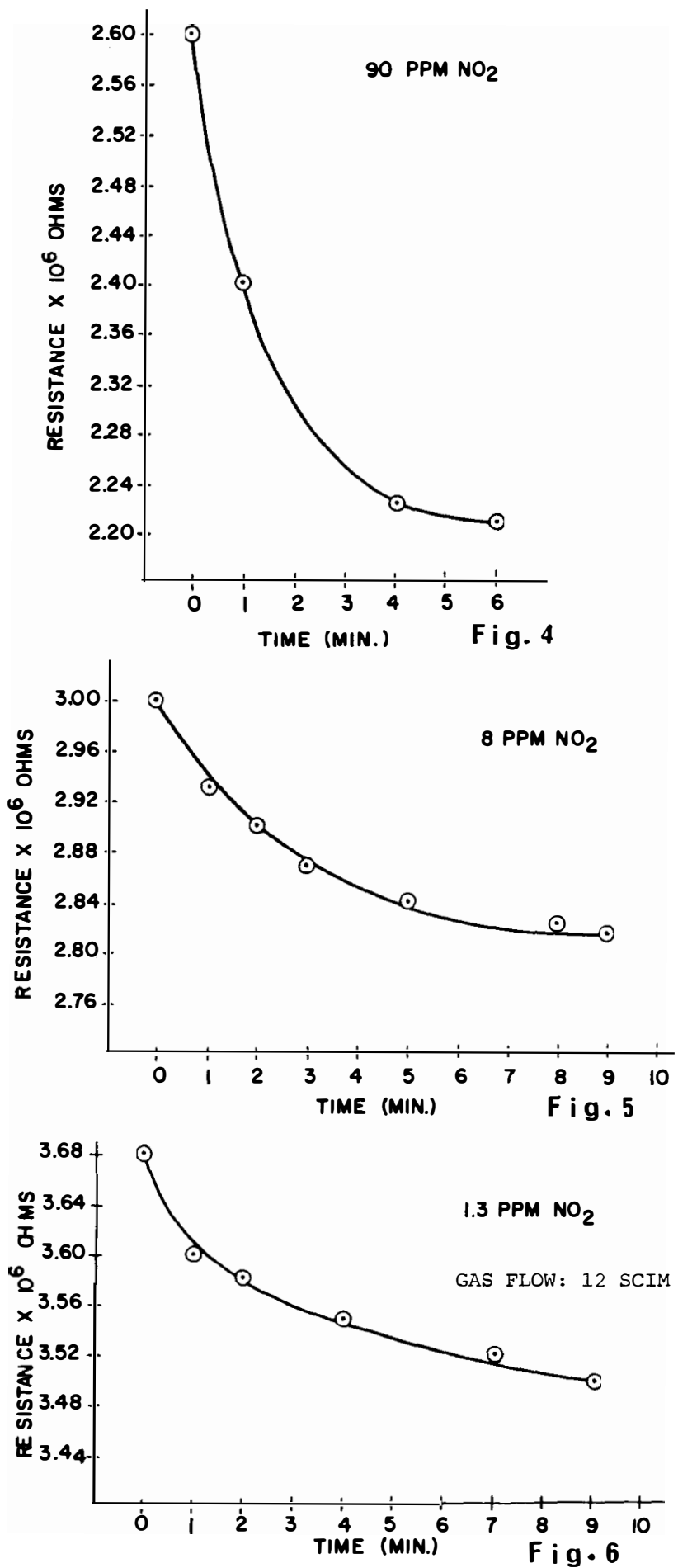

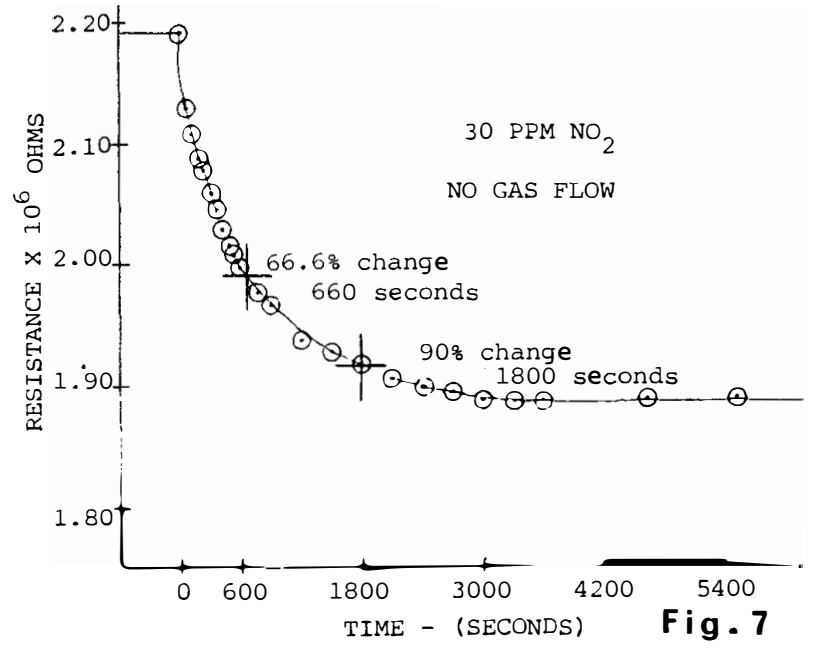

The sensitivity of the pyrolyzed polyimide film to various other gases in air was also examined. The element was not sensitive to reducing gases such as carbon monoxide, methane, and butane, and the oxidizing gas sulfur dioxide.

The electrical resistance of the sensor was measured with a Keithley ElectrometerModel $610 \mathrm{C}$.

\section{SUMMARY}

The pyrolyzed polyaromatic polymer gas sensor described in this paper has a selective response to the presence of nitrogen dioxide in air. It has a design, construction and material composition that makes it unique and useful as a nitrogen dioxide gas sensor. The electrical resistance of the sensor decreases when exposed to nitrogen dioxide in air. This sensor is not sensitive to other gases in air such as carbon monoxide, methane, butane, and sulfur dioxide.

\section{REFERENCES}

[1] R. Bukowski and R. Bright, Some Problems Noted in the use of Taguchi Semiconductor Gas Sensors as Residential Fire/Smoke Detectors, NBS1R 74-591. Washington: National Bureau of Standards Center for Fire Research, December 1974.

[2] J.P. Dolan, "Detection Device," U.S. Patent 3,045,198: July 17, 1962.

[3] J.0. Colla and P.E. Thoma, "Nitrogen Dioxide Sensing Element and Method of Sensing the Presence of Nitrogen Dioxide," U.S. Patent 4,142,400: March 6, 1979

[4] J.0. Colla and P.E. Thoma, "Method of Making a Nitrogen Dioxide Sensing Element," U.S. Patent 4,236,307: December 2, 1980

[5] F. Gulmann and L.E. Lyons, Organic Semiconductors. New York: John Wiley \& Sons, Inc., 1967, Ch.8, pp.472-480.

[6] H. Lee, D. Stoffey and K. Neville, New Linear Polymers. New York: McGraw-Ḧill, Inc., 1967, Ch.8, pp.230-251. 